\title{
Middle East respiratory syndrome: what we learned from the 2015 outbreak in the Republic of Korea
}

\author{
Myoung-don Oh, Wan Beom Park, Sang-Won Park, Pyoeng Gyun Choe, Ji Hwan Bang, Kyoung-Ho Song, \\ Eu Suk Kim, Hong Bin Kim, and Nam Joong Kim
}

Department of Internal Medicine, Seoul National University College of Medicine, Seoul, Korea

Received: February 5, 2018 Accepted: February 13, 2018

\section{Correspondence to}

Myoung-don Oh, M.D.

Department of Internal Medicine, Seoul National University College of Medicine, 101 Daehak-ro, Jongno-gu, Seoul o3o8o, Korea

Tel: $+82-2-2072-2945$

Fax: $+82-2-762-9662$

E-mail: mdohmd@snu.ac.kr

*This paper was contributed by the Korean Society of Infectious Diseases.
Middle East Respiratory Syndrome coronavirus (MERS-CoV) was first isolated from a patient with severe pneumonia in 2012. The 2015 Korea outbreak of MERS$\mathrm{CoV}$ involved 186 cases, including 38 fatalities. A total of $83 \%$ of transmission events were due to five superspreaders, and $44 \%$ of the 186 MERS cases were the patients who had been exposed in nosocomial transmission at 16 hospitals. The epidemic lasted for 2 months and the government quarantined 16,993 individuals for 14 days to control the outbreak. This outbreak provides a unique opportunity to fill the gap in our knowledge of MERS-CoV infection. Therefore, in this paper, we review the literature on epidemiology, virology, clinical features, and prevention of MERS-CoV, which were acquired from the 2015 Korea outbreak of MERSCoV.

Keywords: Coronavirus infections; Middle East respiratory syndrome coronavirus; Coronavirus; Korea; Disease outbreaks

\section{INTRODUCTION}

Middle East respiratory syndrome coronavirus (MERS$\mathrm{CoV}$ ) was first isolated from a patient with severe pneumonia in September 2012 [1]. Since then, as of 31 January 2018, the World Health Organization (WHO) has been notified of 2,143 laboratory-confirmed cases of MERS$\mathrm{CoV}$ infection, including at least 750 deaths, from 27 countries (Fig. 1) [2]. Most of MERS-CoV human infections have occurred in the Arabian Peninsula. Saudi Arabia reported 1,783 cases, including 726 deaths (fatality rate, 40.7\%) [3]. A recent article summarized the current knowledge on the epidemiology, virology, human pathogenesis, clinical management, and prevention of MERS-CoV infection [4]. Another comprehensive review article on risk factors and determinants of transmission of MERS-CoV from human to human in the community and hospital settings has been published recently
[5]. Public Health England also published an extensive review of literature for clinical decision-making support for treatment of MERS-CoV patients [6].

The 2015 Korea outbreak of MERS-CoV is the largest outside the Arabian Peninsula and provides a unique opportunity to fill the gap in our knowledge about MERS-CoV infection. Since it has now been almost 3 years since the 2015 MERS outbreak in the Republic of Korea, we reviewed the literature to summarize the lessons we have learned from the Korea outbreak.

\section{SEARCH STRATEGY}

PubMed databases were searched for studies on MERS cases during the 2015 outbreak in the Republic of Korea. The search terms used were combinations of 'Middle East respiratory syndrome' in all fields and 'Korea' in all 


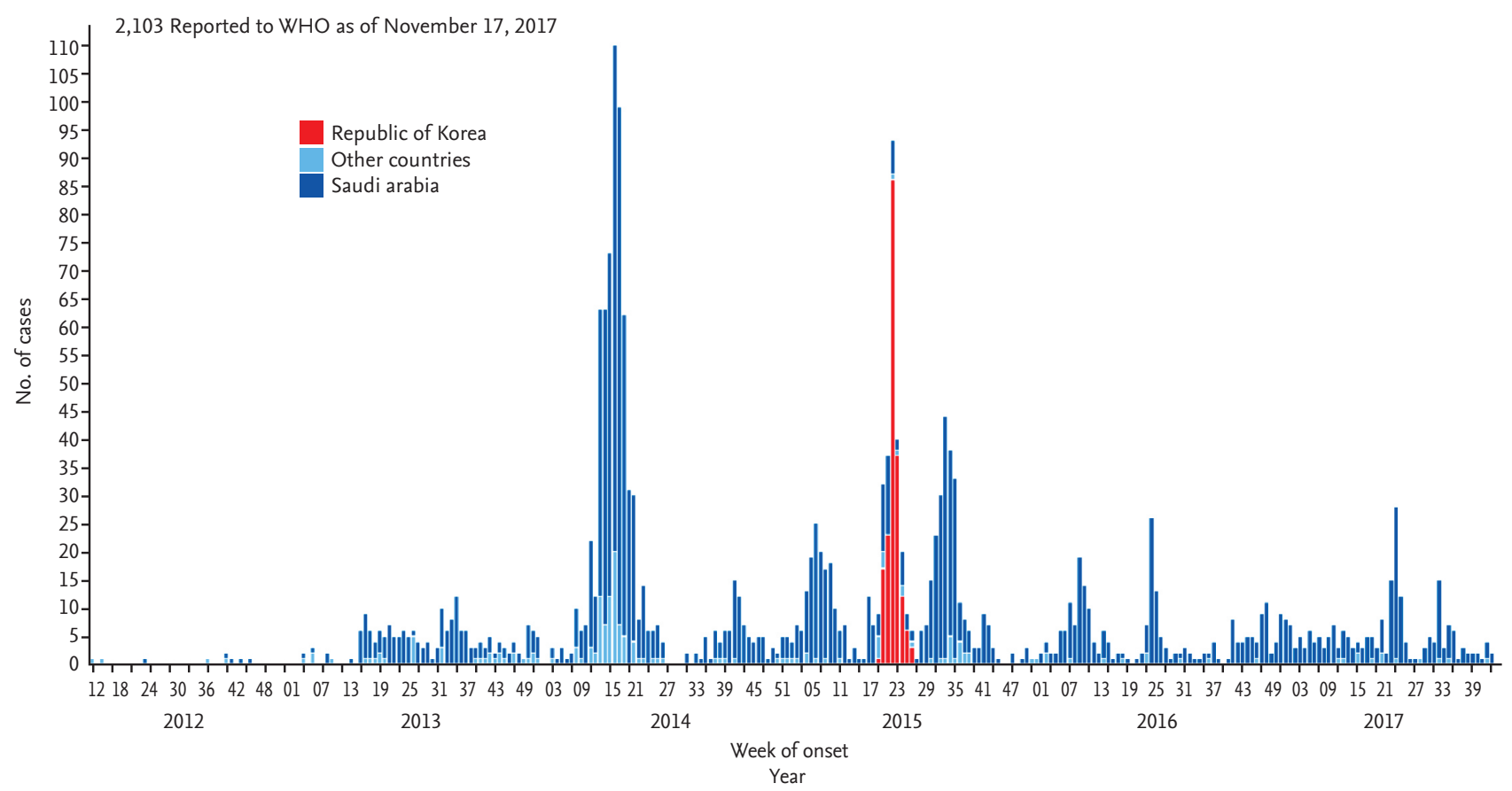

Figure 1. Confirmed global cases of Middle East respiratory syndrome coronavirus reported to World Health Organization (WHO) as of November 17, 2017 ( $\mathrm{n}=2,103)$. Other countries: Algeria, Austria, Bahrain, China, Egypt, France, Germany, Greece, Iran, Italy, Jordan, Kuwait, Lebanon, Malaysia, the Netherlands, Oman, Philippines, Qatar, Thailand, Tunisia, Turkey, United Arab Emirates, United Kingdom, United States of America, Yemen. Adapted from World Health Organization [2].

fields. As of 31 January 2018, a total of 221 articles were retrieved, and 216 of them were written in English. The full texts of the English articles were reviewed and critically assessed.

\section{EPIDEMIOLOGY}

\section{Summary of the Korea outbreak}

The 2015 Korea outbreak of MERS-CoV resulted in 186 cases including 38 fatalities [7]. The index case was a returning traveler from the Middle East. The infection had spread within the hospital, and subsequently to other hospitals because of patient movement, resulting in nosocomial transmission at 16 clinics and hospitals. The epidemic lasted for 2 months, with the government declaring a "virtual" end to the epidemic on July 6, 2015 . In order to control the outbreak, the government quarantined 16,993 individuals for 14 days, and the economic loss was estimated at 9.311 trillion Korean won (8.5 billion US dollars) [8].

\section{The first case of MERS}

The first patient (index case) with MERS-CoV infection was a 68-year-old Korean man returning from the Middle East. He ran a commercial greenhouse business in Bahrain. He flew from Seoul to Bahrain on April 24, 2015, and traveled through the United Arab Emirate and the Kingdom of Saudi Arabia, and came back to Seoul on May 4, 2015. During his 10-day business trip, he did not visit a camel farm or a hospital. He did not eat camel meat or any other camel products. He did not remember meeting any persons with respiratory symptoms [9-12].

Seven days after returning home, on May 11, he developed fever and myalgia. He visited a local clinic on May 12, 14, and 15. His symptoms, however, did not improve and a new non-productive cough developed on 15th May. He visited Pyeongtaek St. Mary's (PTSM) Hospital (65 km south from Seoul), a secondary hospital in Gyeonggi Province. His chest X-ray showed a consolidation in the upper zone of right lung, and he was admitted to the hospital for pneumonia on May 15. Ceftriaxone and amikacin were started, but his pneumonia progressed despite the antibiotic treatment. He was transferred to 
the Samsung Medical Center (SMC), a university-affiliated tertiary hospital in Seoul on May 17 [9]. An infectious disease physician suspected MERS pneumonia and requested a laboratory test from the Korea Centers for Disease Control (CDC). MERS-CoV was confirmed on May 20.

\section{The chain of transmission/hospital to hospital trans- mission}

The chain of transmission was identified in all 186 MERS patients $[13,14]$. Of the 86 healthcare institutions that had taken in MERS-CoV-infected patients, nosocomial transmission occurred in 12 hospitals and four clinics (plus two ambulances) $[13,15,16]$. The epidemiological characteristics are summarized in Table 1 [17]. The epidemic curve is shown in Fig. 2.

\section{The first wave of the epidemic: outbreak at PTSM Hospital}

During his admission from May 15 to 17 at PTSM Hospital, the first patient was unknowingly spreading MERSCoV. Patients, visitors, and healthcare workers (HCWs) were exposed to MERS-CoV. Therefore, by May 20, when the Korea CDC noticed the importation of MERS$\mathrm{CoV}$ into the Republic of Korea, individuals staying on the same floor as the first case had already been exposed to MERS-CoV. As a result, a total of 36 MERS cases occurred at PTSM Hospital. Of them, 26 patients developed symptoms within 14 days after exposure, suggesting they were first-generation cases; the remaining 10 patients may be second-generation cases [7,10].

The mode of transmission of MERS-CoV at PTSM Hospital remains uncertain. In addition to family members of the first patient, only one patient shared the same room (\#8104) with him; all the other cases stayed in other rooms, which were located $>2 \mathrm{~m}$ apart from room \#8104. All patient rooms were equipped with an air ventilating system except for room \#8104. A recent study using a multi-agent modeling framework suggested the transmission occurred via a long-range airborne route or via a combination of a long-range airborne route and direct contact transmission [18]. A chest computed tomography (CT) scan taken in the early stages (day 1 or 2) of illness showed very small, ground glass nodules in the periphery of the lungs, suggesting inhalation of airborne particles [19].
Table 1. Demographic and epidemiological characteristics of 186 patients with MERS-CoV infection [17]

\begin{tabular}{|c|c|}
\hline Characteristic & No. (\%) \\
\hline \multicolumn{2}{|l|}{ Age, yr } \\
\hline$\leq 9$ & 0 \\
\hline $10-19$ & $1(0.5)$ \\
\hline $20-29$ & $13(7.0)$ \\
\hline $30-39$ & $26(14.0)$ \\
\hline $40-49$ & $29(15.6)$ \\
\hline $50-59$ & $42(22.6)$ \\
\hline $60-69$ & $36(19.4)$ \\
\hline $70-79$ & $30(16.1)$ \\
\hline$\geq 80$ & $9(4.8)$ \\
\hline \multicolumn{2}{|l|}{ Sex } \\
\hline Male & $111(59 \cdot 7)$ \\
\hline Female & $75(40.3)$ \\
\hline \multicolumn{2}{|l|}{ Exposure category } \\
\hline Patients & 82 \\
\hline Family member/visitors & 63 \\
\hline Doctors & 8 \\
\hline Nurses & 15 \\
\hline Paid care givers & 8 \\
\hline Technologist at Radiology Department & 2 \\
\hline Ambulance attendants & 2 \\
\hline Security guards & 2 \\
\hline Patient transporter & 1 \\
\hline Employee at IT Department & 1 \\
\hline Exposure category uncertain & 2 \\
\hline \multicolumn{2}{|l|}{ Place of exposure } \\
\hline Hospitals/clinics & $172(92.5)$ \\
\hline Home & $2(1.1)$ \\
\hline Either hospital or home & $6(3.2)$ \\
\hline Ambulance & $3(1.6)$ \\
\hline Uncertain & $3(1.6)$ \\
\hline \multicolumn{2}{|l|}{ Generation of transmission } \\
\hline 1st (index case) & $1(0.5)$ \\
\hline 2nd & $28(15 \cdot 1)$ \\
\hline 3 rd & $120(64.4)$ \\
\hline $4^{\text {th }}$ & $26(14.0)$ \\
\hline Either 2nd, 3rd, or 4th & $8(4 \cdot 4)$ \\
\hline Uncertain & $3(1.6)$ \\
\hline
\end{tabular}

MERS-CoV, Middle East respiratory syndrome coronavirus; IT, information technology. 

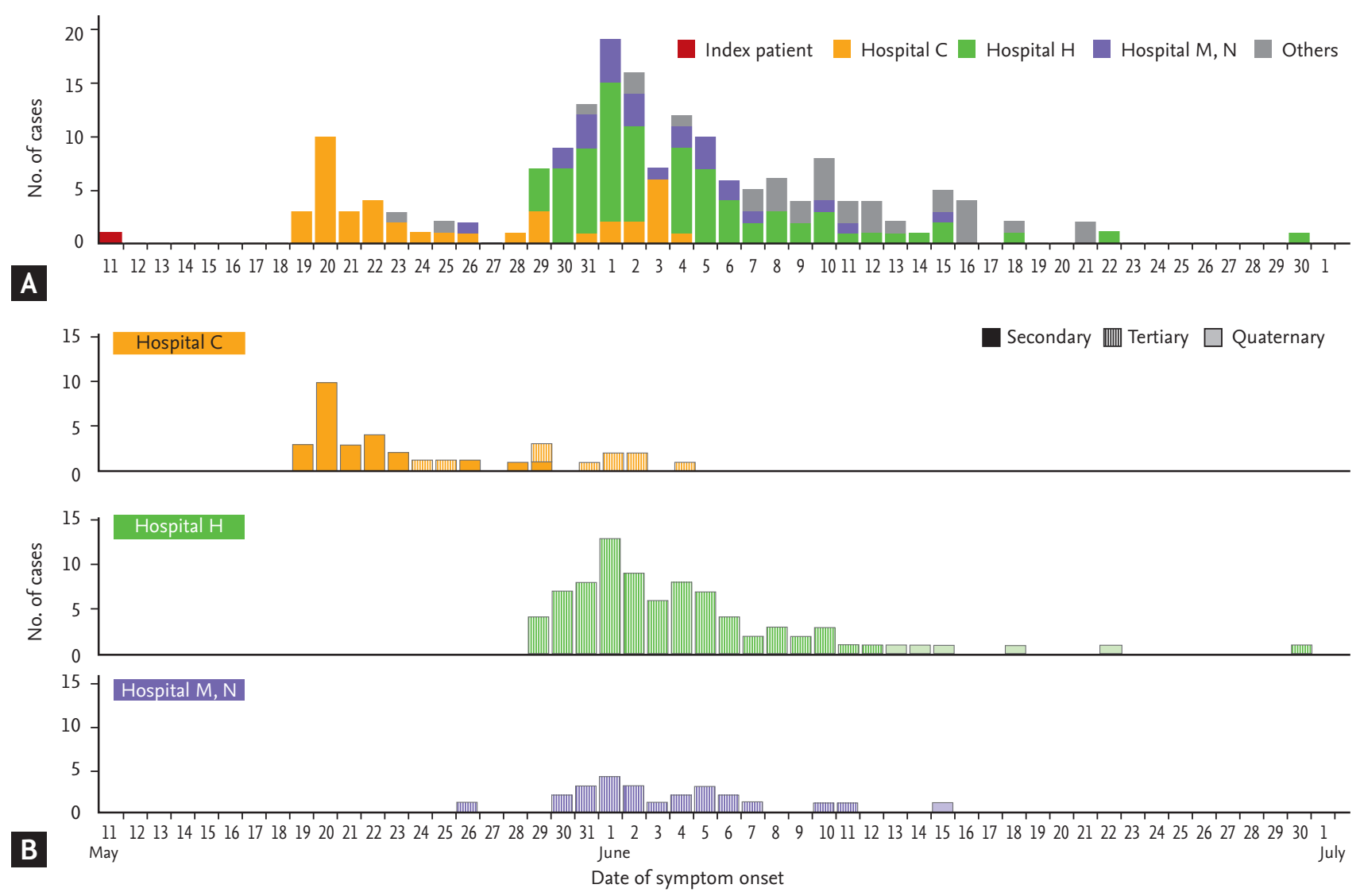

Figure 2. Epidemiological curve for the 2015 Middle East respiratory syndrome coronavirus (MERS-CoV) outbreak in the Republic of Korea. (A) Overall epidemiologic curve by date of symptom onset. Red color denotes the index patient. (B) Epidemic curves for each of the three main clusters. Outbreaks at Hospital C, Hospital H, and Hospital M and N are depicted in yellow, green, and purple color, respectively. Adapted from Korea Centers for Disease Control and Prevention [7].

\section{The index case for the outbreak at the SMC}

The index case (superspreader-1) of the outbreak at the SMC was a 35-year-old man who had been exposed to MERS-CoV at PTSM Hospital during May 15 to 17 [19,20]. He developed a fever on May 21. Despite antibiotic treatment, his pneumonia became aggravated and tachypnea developed, so he eventually visited the emergency room (ER) at SMC on May 27. During his 58-hour stay at the $\mathrm{ER}$, he experienced vigorous coughing and watery diarrhea. On May 29, the Korea CDC found he was staying there. A laboratory test confirmed MERS-CoV infection and he was transferred to the Seoul National University Hospital, a government-designated isolation facility on May 30.

The second wave of the epidemic: the outbreak at SMC Many individuals had been exposed to the superspreader-1 at the ER, and contact tracing identified 675 patients, an estimated 683 visitors, and $218 \mathrm{HCWs}$ as contacts of superspreader-1. Of them, 278 were quarantined and 617 were under active monitoring. As a result of exposure to superspreader-1, 82 had laboratory-confirmed MERSCoV infection, and an additional 10 were secondarily infected from them $[20,21]$.

\section{The outbreaks in Daejeon: Daechung \& Geonyang Hospitals}

The index case (superspreader-2) for the Daejeon (100 $\mathrm{km}$ south from Pyeontaek city) outbreak was infected at PTSM Hospital. He developed symptoms on May 20 and was admitted to Daechung Hospital on May 22. As his pneumonia progressed despite the treatments, he was transferred to Geonyang Hospital on May 28. A total of 25 secondary cases (14 in Daechung Hospital and 11 in Geonyang Hospital) were detected. Although superspreader-2 caused the two hospital outbreaks, the me- 
dian time of incubation (8.8 days vs. 4.6 days), secondary attack rates ( $4.7 \%$ vs. $3.0 \%$ ), and case fatality rate $(28.6 \%$ vs. $63.6 \%)$ were different between the two outbreaks. The high fatality rate was associated with pre-existing pneumonia or poor underlying pulmonary function [22-24].

\section{One patient traveled to China}

A 44-year-old male, who had been exposed to the first index case on May 16, developed back pain on May 21. He is a son of the third MERS case. His sister had also been exposed to MERS-CoV and was confirmed to have an MERS-CoV infection on May 25. On May 26, against medical advice, he flew to Hong Kong and subsequently travelled to Huizhou through an entry point in Shenzhen City, Guangdong Province. The Korea CDC notified the WHO of his travel, and the Chinese health authority found him on May 27 and immediately isolated him. He was confirmed to have MERS-CoV infection on May 29. The Chinese authority identified 78 close contacts. After 14 days of quarantine, none of the contacts presented symptoms and all tested negative for MERS$\operatorname{CoV}[25,26]$.

\section{Epidemiological characteristics}

Epidemiological characteristics have been reported by several groups (Table 2) [7,16,20,21,23,27-30]. The defining epidemiological characteristics were superspreading events at hospitals [30-32]. Early superspreading events generated a disproportionately large number of second- ary infections, and the transmission potential decreased sharply in subsequent generations [30,33]. A total of $83 \%$ of transmission events were due to five superspreaders, and $44 \%$ of the 186 MERS cases were in-patients who had been exposed within the hospitals [7]. The spreaders transmitted MERS-CoV from days 1 to 11 of their illness (median, 7 days), and the number of patients infected by each spreader ranged from 1 to 84 (interquartile range, 1 to 12 ) [27].

The median incubation period and serial interval was 7 days and 12.5 days, respectively [7,34]. Ro ranged from 2.5 to 7.2 , higher than the previous estimate of $<1$ [35]. It was estimated at 4.04 for the outbreak cluster in PTSM Hospital, and 5.0 for the outbreak in SMC [36]. A mathematical modeling study demonstrated that although Ro $<1$ overall, cluster sizes of over 150 cases are not unexpected for MERS-CoV infection [37].

Compared with the non-spreaders, the spreaders had a higher frequency of fever $\left(\geq 38.5^{\circ} \mathrm{C}\right)$ and chest infiltrates in more than three lung zones, and longer non-isolated in-hospital days [27]. The spreaders had higher viral load in sputum samples with the cycle thresholds for the upE and ORFia genes of 22.7 vs. 27.2 and 23.7 vs. 27.9, respectively. The spreaders with more than three transmissions had higher numbers of contacts and ER visits [38]. A brief exposure of a 10-minute stay and 2 minutes of talking was enough for the transmission of MERS$\mathrm{CoV}[39]$.

Table 2. Epidemiological findings and clinical outcomes of 2015 MERS-CoV outbreak in the Republic of Korea

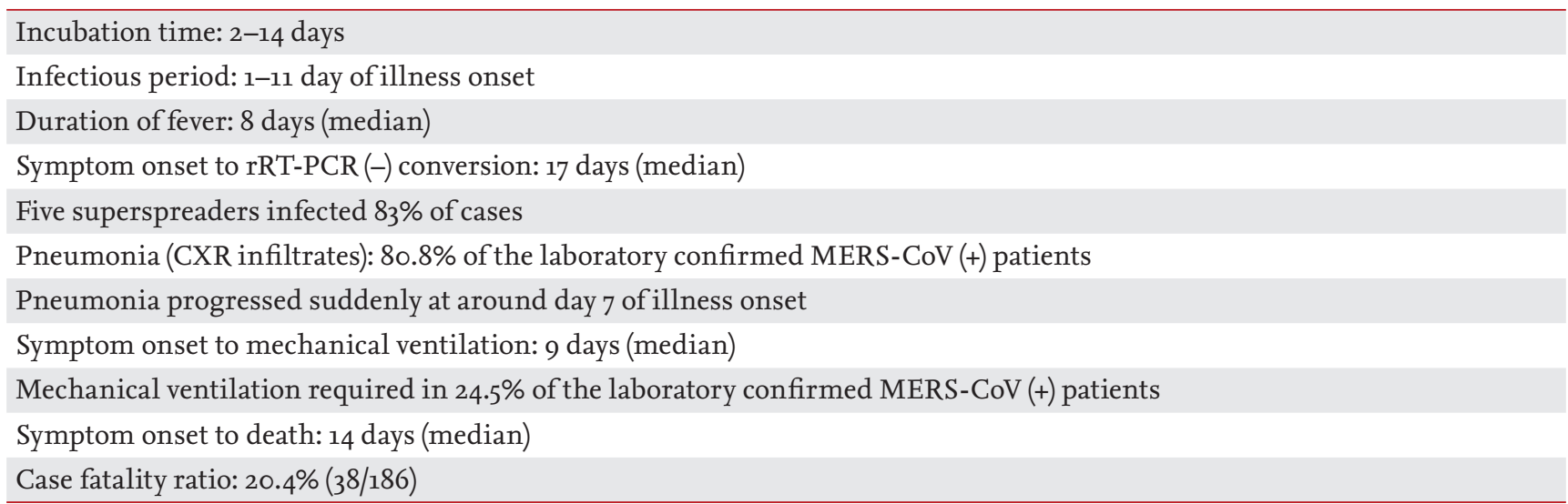

MERS-CoV, Middle East respiratory syndrome coronavirus; rRT-PCR, real-time reverse transcription polymerase chain reaction; CXR, chest X-ray. 


\section{VIROLOGY}

\section{Characterization of the MERS-CoV isolates}

The whole genome sequences of MERS-CoV isolated from the Korea outbreak were reported [26,40-43]. The virus most similar to the Korean isolates was a camel virus (Camel/Riyadh/Ry159/2015) that belonged to lineage 5 , a recombinant of lineage 3 and 4 [44,45]. Viruses from lineage 5 had been predominant in Saudi Arabian camels since November 2014, but human viruses of this lineage were reported from February 2015 [44]. A phylogenetic study of spike glycoprotein genes also showed the Korean strains were closely related to the viral strains from Riyadh, Saudi Arabia [46]. In a molecular study, 11 of 13 MERS-CoV genome had an I529T mutation and one $\mathrm{D}_{510} \mathrm{G}$ mutation in the receptor binding domain of viral spike protein, resulting in reduced affinity to the human cognate receptor, CD26 [47]. Heterogeneity analysis revealed the combined frequency of $\mathrm{I}_{529} \mathrm{~T}$ and D510G was high (87.7\%), although the frequency of both mutations varied greatly among specimens [48].

Another genome sequence study also reported deletions of 414 and 419 nucleotides between $\mathrm{ORF}_{5}$ and the $\mathrm{E}$ protein, suggesting that the virus might be defective in its ability to package MERS CoV [49]. A microevolution study found no evidence of changes in the evolutionary rate [43]. However, whether the transmissibility and virulence of the Korean isolates are different from those of the previous isolates from the Kingdom of Saudi Arabia remains to be determined by phenotypic assays.

\section{Kinetics of virus shedding}

A viral shedding study showed that the copies of MERSCoV RNA detected by real-time reverse transcription polymerase chain reaction (rRT-PCR) in respiratory samples peaked during week 2 , and the median value was $7.21 \log _{10}$ in the severe group and $5.54 \log _{10}$ in mild cases [50]. The study also showed that viral titers were higher in throat samples than in nasopharyngeal samples. Another study also demonstrated higher viral loads were associated with severity and mortality [51].

\section{Antibody response kinetics}

After MERS-CoV infection, antibody responses developed by the third week of illness in most patients [52]. Seroconversion rates increased with the increase of dis- ease severity. In a serologic study of 42 MERS patients, the seroconversion rate was $\%$ in asymptomatic infection, $60.0 \%$ in symptomatic infection without pneumonia, $93.8 \%$ in pneumonia without respiratory failure, and $100 \%$ in pneumonia with respiratory failure [53]. The serological response remained detectable for $>12$ months in all survivors (11/11) who had severe disease. Antibody titers were not detectable in four of six patients who had mild pneumonia, suggesting that MERS-CoV seroepidemiological studies may underestimate the extent of mild and asymptomatic infection [54].

\section{CLINICAL FEATURES}

\section{Clinical manifestations}

The Korean Society of Infectious Diseases compiled the clinical data of the 186 MERS patients [55]. The median age was 55 years (range, 16 to 86). The male to female ratio was 3:2. The most common coexisting medical conditions were hypertension (31.7\%), diabetes (18.8\%), solid organ malignancy (13.4\%), and chronic lung disease (10.2\%). Patients with MERS-CoV infection developed a spectrum of illnesses, ranging from asymptomatic to fulminant pneumonia with fatal outcome. The respiratory symptoms were similar to other acute viral respiratory infections. At the time of presentation, fever had developed in $81.7 \%$, cough in $56.7 \%$, and sputum in $39.8 \%$ of patients. Symptoms of upper respiratory-tract infections were infrequent: sore throat was present in 9.1\% and rhinorrhea in $1.6 \%$ of patients. Gastrointestinal symptoms were also observed: diarrhea was present in $19.4 \%$, nausea or vomiting in $14.0 \%$, and abdominal pain in $8.1 \%$ of patients. Diarrhea may be due to the side effect of lopinavir/ritonavir, as $87 \%$ of the patients received antiviral drugs for MERS-CoV treatment [55]. In the early stages of illness, cough and sputum were not prominent even in patients who later developed overt pneumonia [56]. At admission, 68\% (123/180) of patients had abnormalities on chest radiographs, while $80.8 \%$ (147/182) of them developed the abnormalities during the course of the disease [55]. Sudden progression of pneumonia occurred around day 7 of illness [50,57]. Predictive factors for development of pneumonia included older age, high fever, thrombocytopenia, lymphopenia, C-reactive protein $(\mathrm{CRP}) \geq 2 \mathrm{mg} / \mathrm{dL}$, and a high viral load 
in sputum (threshold cycle value of rRT-PCR < 28.5) [58]. Forty-five patients $(24.5 \%)$ were treated with mechanical ventilation and 15 patients $(8.2 \%)$ needed extracorporeal membrane oxygenation [55]. The typical course of pneumonia is shown in Fig. 3.

Acute kidney injury (AKI) developed in $14.0 \%$ of the patients, $42.7 \%$ (44/103) had proteinuria, and 35.0\% (36/103) had hematuria. Fifteen patients were treated with renal replacement therapy [55]. Old age is an independent risk factor for the occurrence of AKI [59]. Neuromuscular manifestations were not uncommon; hypersomnolence, weakness and tingling in the extremities were reported during the treatment of MERS, suggesting Guillain-Barré syndrome or virus-related sensory neuropathy [6o].

\section{Radiological findings}

Serial changes in chest radiographs was reported in five patients [56]. Chest CT scans revealed rapidly developed multifocal nodular consolidations with ground-glass opacity halo and mixed consolidation, mainly in the dependent and peripheral areas [61].

\section{Laboratory findings}

There are few laboratory findings specific to MERS-CoV infection, although monocytosis with normal white blood cell count and low CRP level were more common in MERS patients at initial presentation $[57,62]$.

\section{Laboratory diagnosis of MERS-CoV}

The guidelines for the molecular diagnosis of MERS$\mathrm{CoV}$ infection have been published by the Korean Society for Laboratory Medicine [63,64]. Specimen type and quality is important in the laboratory diagnosis of MERS-CoV infection. Lower respiratory-tract samples, such as sputum and tracheal aspirates, have higher viral loads than upper respiratory-tract samples [50]. However, MERS patients may not shed the virus during the early stage of their illness. Therefore, initial negative results should not rule out the possibility of MERS [65], and patients suspected of having MERS-CoV infection should be retested using a lower respiratory-tract sample $[63,66]$. When sputum cannot be obtained, throat swabs may be an alternative source of diagnostic samples [50]. Special attention should be given to diagnosing MERS-CoV infection in immunocompromised patients, as they may present with atypical features, such as a longer incubation period, a longer period from initial PCR positivity to symptom onset, and persistent viral shedding [67].

\section{Antiviral treatment}

An antiviral treatment guideline has been published by the writing committee with support from the Korean Society of Infectious Diseases and the Korean Society for Chemotherapy [68]. The guideline recommended a tri-

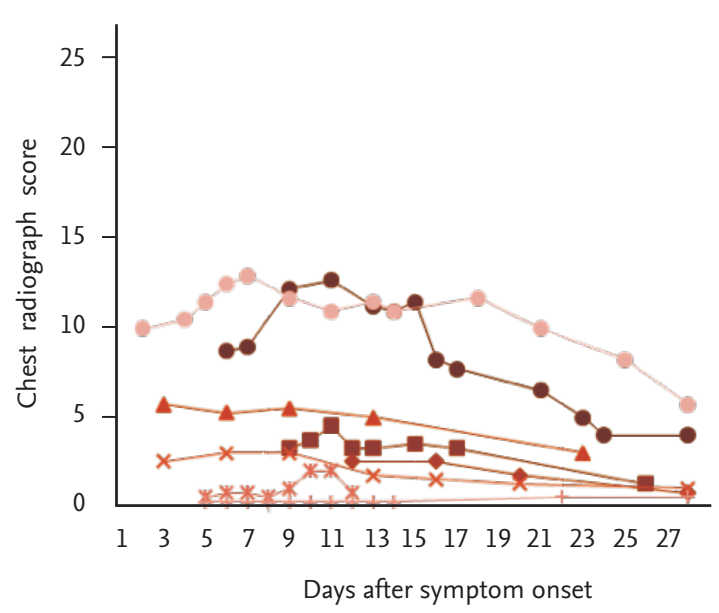

\section{A}

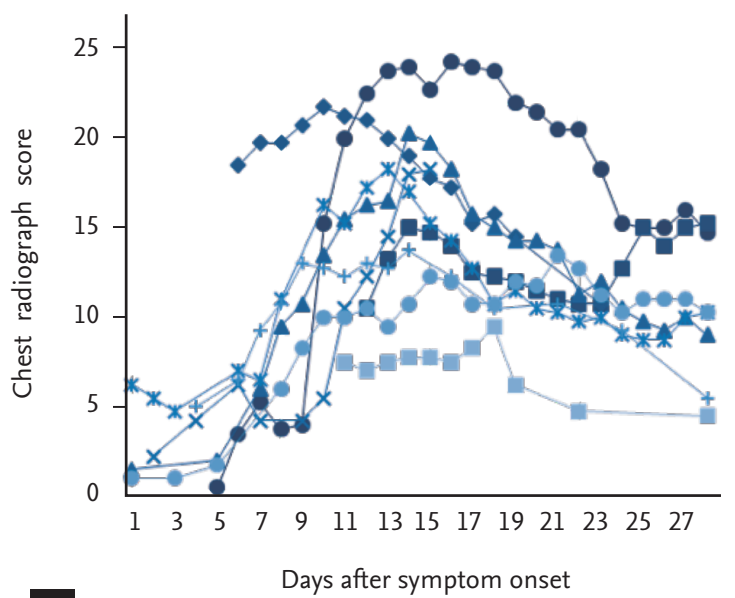

Figure 3. Progression of Middle East respiratory syndrome (MERS) pneumonia. (A) Severe cases. (B) Mild cases. In severe cases, pneumonia progressed suddenly around 7 days after symptom onset. Adapted from Oh et al., with permission from Massachusetts Medical Society [50]. 

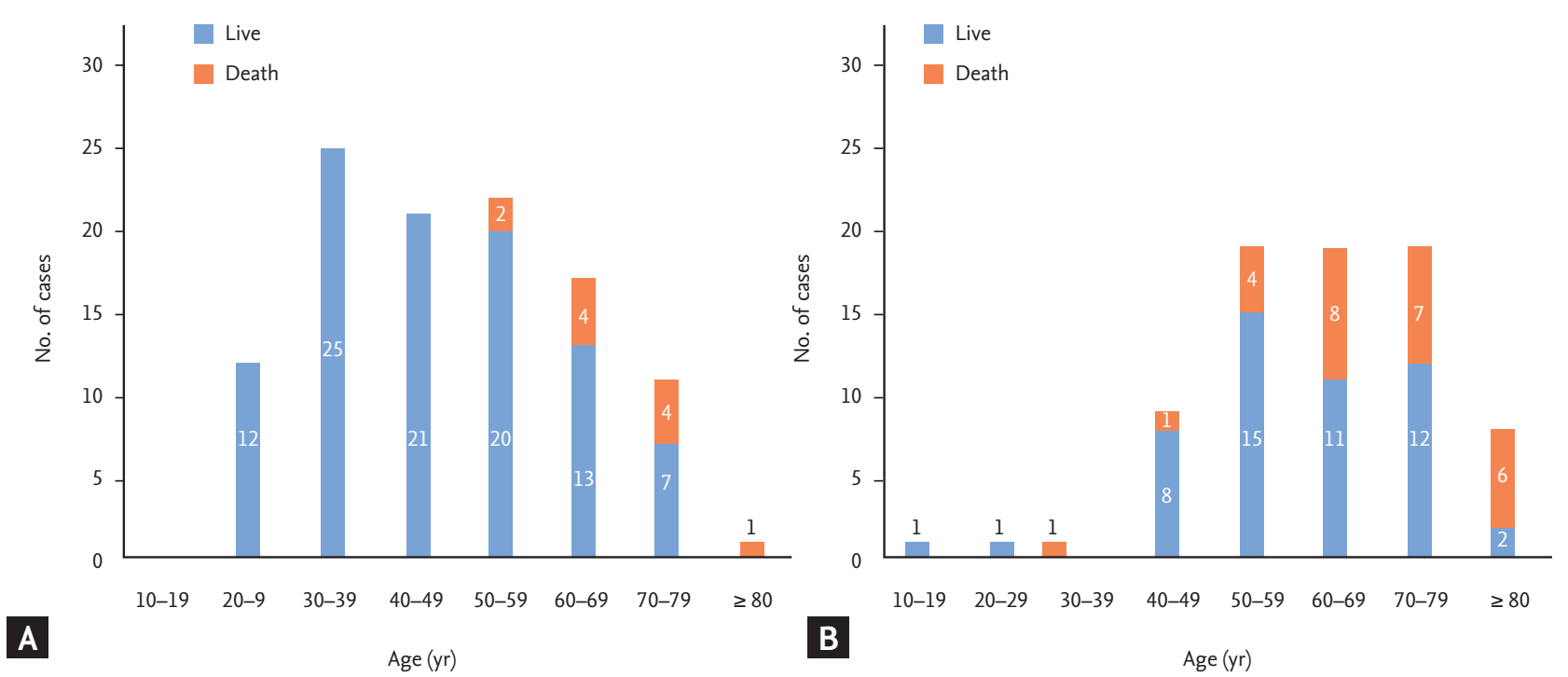

Figure 4. Case fatality ratio of Middle East respiratory syndrome during the 2015 Korea outbreak. Case fatality ratio was $10.1 \%$ (11/109) in patients without underlying diseases (A), and 35.1\% (27/77) with underlying diseases (B). Overall case fatality ratio was $20.4 \%(38 / 186)$.

ple combination regimen of type 1 interferon, ribavirin, and lopinavir/ritonavir for 10 to 14 days. However, the guideline was mostly based on expert opinions and further study for the optimal antiviral treatment in MERS is warranted.

\section{Risk factors for mortality and prognosis}

The median duration of fever was 8 days. The median time to negative conversion of MERS-CoV in sputum samples by rRT-PCR was 17 days (range, 4 to 45) [55].

The median time from symptom onset to death was 14 days. The case fatality rate was $20.4 \%$ (38/186) (Fig. 4). The in-hospital mortality, 7-day mortality, and 28-day (from symptom onset) mortality were 19.4\% (36/186), $3.8 \%$ (7/186), and $17.7 \%$ (33/186), respectively [55].

Host factors associated with mortality were old age (> 60 years), smoking history, pre-existing pneumonia, abnormal renal function, and comorbid conditions [24,6971]. Low albumin, altered mentality, and high pneumonia severity index score at admission were risk factors for mortality [69]. MERS-CoV RNA in blood samples was detected in $33 \%$ (7/21) of patients at presentation, and it was associated with a worse clinical outcome [72]. A shorter incubation period was also associated with an increased risk of death $[24,73]$.

A pregnant woman infected with MERS-CoV in her
35 weeks of gestational age developed dyspnea and her chest radiograph showed diffuse infiltrates in the left lower lung zone. She recovered from the infection and delivered a healthy full-term baby without vertical MERS-CoV transmission [74].

A patient developed organizing pneumonia 7 days after the resolution of MERS-CoV infection. He was successfully treated with corticosteroids [75].

In a mental health study, $7.6 \%$ of 1,656 patients who were quarantined showed symptoms of anxiety, and $6.4 \%$ reported feelings of anger during the 2 weeks of quarantine [76]. Mental health support, accurate information, and appropriate supplies, including food, clothes, and accommodation, should be provided to isolated persons [76]. A case of possible transfusion-related acute lung injury following transfusion of convalescent plasma was also reported [77].

\section{INFECTION CONTROL AND PREVENTION}

\section{Guidelines for infection control and prevention}

A comprehensive "MERS infection prevention and control guideline for healthcare facilities" was drafted by the guideline development committee with generous support from Korean Academic Societies [78]. The 
guideline included practical aspects of infection control and prevention based on the experience from the Korea outbreak, such as the composition of members for the MERS emergency committee, a space plan for an anteroom for donning and doffing, isolation of in-patients and HCWs in a hospital affected by an outbreak, and management of the deceased and autopsy [78].

The hemodialysis unit may become an epicenter for MERS-CoV outbreak because hemodialysis patients must receive renal replacement therapy even during the outbreak, and the risk of exposure to MERS-CoV continues. During the Korea outbreak, a hemodialysis unit was found to have a MERS patient, and a total of 104 patients and $18 \mathrm{HCWs}$ were exposed to MERS-CoV. With support from the Korean Society of Nephrology, the dialysis unit could continue to operate while the exposed patients were isolated in the unit. Fortunately, no further transmission occurred at the unit [79]. After this successful experience, the Society published a clinical practice guideline for hemodialysis facilities dealing with MERS patients [8o].

The Korea outbreak was driven by the superspreaders who visited multiple healthcare facilities; thus, generating a large number of secondary cases. Limiting unnecessary contacts with patients with respiratory symptoms in healthcare settings, especially in emergency departments, is of critical importance [33].

\section{Environmental contamination}

MERS-CoV could survive for longer than 48 hours at $20^{\circ} \mathrm{C}$ and $40 \%$ of relative humidity, suggesting contact or fomite transmission might occur in healthcare settings [81]. MERS-CoV was detected by rRT-PCR in specimens taken from the medical equipment [82-84]. MERS$\mathrm{CoV}$ was also isolated by cell culture of the air and swab samples taken from a MERS isolation unit, suggesting extensive contamination of the isolation unit $[85,86]$. Of the 186 cases, $23 \%$ were infected by undocumented contact between cases (i.e., indirect transmission of MERS$\mathrm{CoV}$ via environmental contact) [87]. Therefore, fomites with possible MERS-CoV contamination should be sanitized, and a minimum room ventilation rate of six air changes per hour should be implemented to minimize recirculation of pathogen-bearing droplets. Meticulous environmental cleaning may be important for preventing transmission in healthcare settings.

\section{Healthcare workers and MERS-CoV infection}

There was a case of a 39-year-old female nurse who was infected with MERS-CoV during a cardiopulmonary resuscitation lasting 1 hour for a MERS patient who had pneumonia and hemoptysis [88]. Serological surveillance conducted after the MERS outbreak for asymptomatic infection among HCWs involved in the direct care of MERS patients showed that $0.3 \%$ (2/737) of them were MERS-CoV IgG positive by an indirect immunofluorescent assay. Among the HCWs who did not use appropriate personal protective equipment (PPE), seropositivity was $0.7 \%$ (2/294) compared with ०\% (o/443) in HCWs with appropriate PPE use [89]. Another serological survey also showed that none of the $285 \mathrm{HCWs}$ were positive for MERS-CoV immunoglobulin G, although 38.2\% (109/285) of the HCWs reported experiencing MERS-like symptoms while caring for the MERS patients [90]. In a third study, o of 189 HCWs showed seroconversion by a plaque reduction neutralization test, although $20 \%$ to $25 \%$ of HCWs reported MERS-like symptoms [91].

During the outbreak in SMC, all HCWs assigned to MERS patients were screened for MERS-CoV, regardless of the presence or absence of symptoms. Of the 591 HCWs, three (0.5\%) asymptomatic HCWs (two nurses and one physician) were found to be MERS-CoV (+), but they did not transmit the virus to others [21]. In another study, an asymptomatic nurse without PPE contacted 82 HCWs, including 33 close contacts who were exposed within $2 \mathrm{~m}$ from the index nurse and were not using PPE. None of the exposed HCWs were infected [92].

However, the potential for transmission from asymptomatic rRT-PCR positive individuals is still unknown. Therefore, asymptomatic HCWs who are rRT-PCR-positive for MERS-CoV should be isolated and should not return to work until two consecutive respiratory-tract samples test negative on rRT-PCR [93].

\section{Control of the outbreak by private-public collaboration}

The government requested the Korean Society of Infectious Diseases to participate in the control of the MERS outbreak. On June 8, 2015, the Society organized the Rapid Response Team, consisting of 15 infectious-disease doctors and two infection-control professionals [94]. Critical suggestions to prevent future epidemics were made regarding a rapid alerting system for index cases, provision of a sufficient airborne infection isola- 
Table 3. Lessons learned from the 2015 outbreak of MERS-CoV in the Republic of Korea

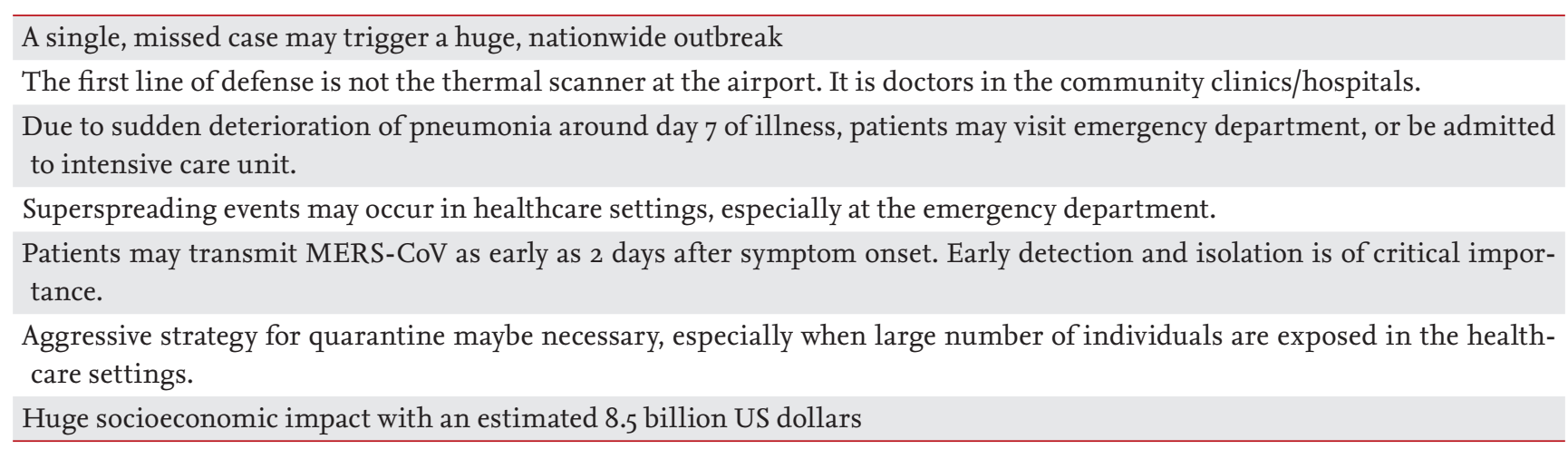

MERS-CoV, Middle East respiratory syndrome coronavirus.

tion facility, education and training of HCWs for important infectious diseases, and overcrowding and visitor control in the hospital [95].

\section{CONCLUSIONS}

The 2015 Korea outbreak was the largest outbreak outside of the Middle East. Researchers had a unique opportunity to compare the nature of MERS-CoV infection with the Middle East experience. The outbreak unveiled the weak points of infrastructure in our medical system, especially of preparedness for emerging global infectious diseases. Nosocomial transmission was one of the core features of MERS-CoV infection. The introspection for loose medical referral systems, overcrowding at the ER, a lack of expert resources and infection control infrastructure, and lack of organized preparedness for medical crises prompted the government to reform the healthcare system, and healthcare sectors to invest further in infectious diseases and infection control. Although the improvement is still ongoing, the speed and content are still currently insufficient. International cooperation to prepare for and defeat emerging infectious diseases should also be emphasized. Lessons we learned from the outbreak are summarized in Table 3.

\section{Conflict of interest}

No potential conflict of interest relevant to this article was reported.

\section{REFERENCES}

1. Zaki AM, van Boheemen S, Bestebroer TM, Osterhaus $\mathrm{AD}$, Fouchier RA. Isolation of a novel coronavirus from a man with pneumonia in Saudi Arabia. N Engl J Med 2012;367:1814-1820.

2. World Health Organization. Middle East respiratory syndrome coronavirus (MERS-CoV) [Internet]. Geneva: World Health Organization, c2018 [cited 2018 Feb 8]. Available from: http://who.int/emergencies/mers-cov/en/.

3. Ministry of Health Kingdom of Saudi Arabia. MERSCoV daily update [Internet]. Riyadh (SA): Ministry of Health Kingdom of Saudi Arabia, c2014 [cited 2018 Feb 8]. Available from: https://www.moh.gov.sa/en/CCC/ PressReleases/Pages/statistics-2018-01-27-001.aspx.

4. Arabi YM, Balkhy HH, Hayden FG, et al. Middle East respiratory syndrome. N Engl J Med 2017;376:584-594.

5. Hui DS, Azhar EI, Kim YJ, Memish ZA, Oh MD, Zumla A. Middle East respiratory syndrome coronavirus: risk factors and determinants of primary, household, and nosocomial transmission. Lancet Infect Dis. 2018 In Press.

6. Public Health England. Treatment of MERS-CoV: information for clinicians. Clinical decision-making support for treatment of MERS-CoV patients [Internet]. London (UK): Public Health England, 2017 [cited 2018 Feb 8]. Available from: https://www.gov.uk/government/ uploads/system/uploads/attachment_data/file/638628/ MERS_CoV_guidance_for_clinicians.pdf.

7. Korea Centers for Disease Control and Prevention. Middle East respiratory syndrome coronavirus outbreak in the Republic of Korea, 2015. Osong Public Health Res Perspect 2015;6:269-278. 
8. Oh MD. The Korean Middle East respiratory syndrome coronavirus outbreak and our responsibility to the global scientific community. Infect Chemother 2016;48:145-146.

9. Lee JY, Kim YJ, Chung EH, et al. The clinical and virological features of the first imported case causing MERS-CoV outbreak in South Korea, 2015. BMC Infect Dis 2017;17:498.

10. Kim KM, Ki M, Cho SI, et al. Epidemiologic features of the first MERS outbreak in Korea: focus on Pyeongtaek St. Mary's Hospital. Epidemiol Health 2015;37:e2015041.

11. Yang JS, Park S, Kim YJ, et al. Middle East respiratory syndrome in 3 persons, South Korea, 2015. Emerg Infect Dis 2015;21:2084-2087.

12. Park YS, Lee C, Kim KM, et al. The first case of the 2015 Korean Middle East respiratory syndrome outbreak. Epidemiol Health 2015;37:e2015049.

13. FluTrackers. South Korea coronavirus MERS case list: including imported and exported cases. Ministry of Health \& WHO confirmed data only: 2015 outbreak [Internet]. Winter Park (FL): FluTrackers, c2018 [cited 2018 Feb 8]. Available from: https://flutrackers.com/forum/forum/novelcoronavirus-ncov-mers-2012-2014/novel-coronavirus-whochp-wpro-ecdc-oie-fao-moa-reports-and-updates/southkorea-coronavirus/732065-south-korea-coronavirus-merscase-list-including-imported-and-exported-cases-ministryof-health-who-confirmed-data-only-2015-outbreak.

14. Korea Broadcasting System Digital News. MERS-CoV infection: current status-interactive and infographics [Internet]. KBS Digital News, c2013 [cited 2018 Feb 8]. Available from: http://dj.kbs.co.kr/resources/2015-06-o8/.

15. Lee SS, Wong NS. Probable transmission chains of Middle East respiratory syndrome coronavirus and the multiple generations of secondary infection in South Korea. Int J Infect Dis 2015;38:65-67.

16. Kim KH, Tandi TE, Choi JW, Moon JM, Kim MS. Middle East respiratory syndrome coronavirus (MERS$\mathrm{CoV}$ ) outbreak in South Korea, 2015: epidemiology, characteristics and public health implications. J Hosp Infect 2017;95:207-213.

17. Ministry of Health and Welfare. The 2015 MERS outbreak in the Republic of Korea: learning from MERS (The White Paper). Seoul (KR): Ministry of Health and Welfare, 2016:473.

18. Xiao S, Li Y, Sung M, Wei J, Yang Z. A study of the probable transmission routes of MERS-CoV during the first hospital outbreak in the Republic of Korea. Indoor
Air 2018;28:51-63.

19. Oh MD, Choe PG, Oh HS, et al. Middle East respiratory syndrome coronavirus superspreading event involving 81 persons, Korea 2015. J Korean Med Sci 2015;30:1701-1705.

20. Cho SY, Kang JM, Ha YE, et al. MERS-CoV outbreak following a single patient exposure in an emergency room in South Korea: an epidemiological outbreak study. Lancet 2016;388:994-1001.

21. Park GE, Ko JH, Peck KR, et al. Control of an outbreak of Middle East respiratory syndrome in a tertiary hospital in Korea. Ann Intern Med 2016;165:87-93.

22. Park SH, Kim YS, Jung Y, et al. Outbreaks of Middle East respiratory syndrome in two hospitals initiated by a single patient in Daejeon, South Korea. Infect Chemother 2016;48:99-107.

23. Park JW, Lee KJ, Lee KH, et al. Hospital outbreaks of Middle East respiratory syndrome, Daejeon, South Korea, 2015. Emerg Infect Dis 2017;23:898-905.

24. Nam HS, Park JW, Ki M, Yeon MY, Kim J, Kim SW. High fatality rates and associated factors in two hospital outbreaks of MERS in Daejeon, the Republic of Korea. Int J Infect Dis 2017;58:37-42.

25. Wu J, Yi L, Zou L, Zhong H, et al. Imported case of MERSCoV infection identified in China, May 2015: detection and lesson learned. Euro Surveill 2015;20:21158.

26. Wang Y, Liu D, Shi W, et al. Origin and possible genetic recombination of the Middle East respiratory syndrome coronavirus from the first imported case in china: phylogenetics and coalescence analysis. MBio 2015;6:e01280-15.

27. Kang CK, Song KH, Choe PG, et al. Clinical and epidemiologic characteristics of spreaders of Middle East respiratory syndrome coronavirus during the 2015 outbreak in Korea. J Korean Med Sci 2017;32:744-749.

28. Park SH, Kim WJ, Yoo JH, Choi JH. Epidemiologic parameters of the Middle East respiratory syndrome outbreak in Korea, 2015. Infect Chemother 2016;48:108-117.

29. Park HY, Lee EJ, Ryu YW, et al. Epidemiological investigation of MERS-CoV spread in a single hospital in South Korea, May to June 2015. Euro Surveill 2015;20:1-6.

30. Chowell G, Abdirizak F, Lee S, et al. Transmission characteristics of MERS and SARS in the healthcare setting: a comparative study. BMC Med 2015;13:210.

31. Chun BC. Understanding and modeling the super-spreading events of the Middle East respiratory syndrome outbreak in Korea. Infect Chemother 2016;48:147-149.

32. Ki M. 2015 MERS outbreak in Korea: hospital-to-hospital 
transmission. Epidemiol Health 2015;37:e2015033.

33. Nishiura H, Endo A, Saitoh M, et al. Identifying determinants of heterogeneous transmission dynamics of the Middle East respiratory syndrome (MERS) outbreak in the Republic of Korea, 2015: a retrospective epidemiological analysis. BMJ Open 2016;6:0009936.

34. Virlogeux V, Fang VJ, Park M, Wu JT, Cowling BJ. Comparison of incubation period distribution of human infections with MERS-CoV in South Korea and Saudi Arabia. Sci Rep 2016;6:35839.

35. Zhang XS, Pebody R, Charlett A, et al. Estimating and modelling the transmissibility of Middle East respiratory syndrome coronavirus during the 2015 outbreak in the Republic of Korea. Influenza Other Respir Viruses 2017;11:434-444.

36. Choi S, Jung E, Choi BY, Hur YJ, Ki M. High reproduction number of Middle East respiratory syndrome coronavirus in nosocomial outbreaks: mathematical modelling in Saudi Arabia and South Korea. J Hosp Infect 2017 Sep 25 [Epub]. https://doi.org/10.1016/j.jhin.2017.09.017.

37. Kucharski AJ, Althaus CL. The role of superspreading in Middle East respiratory syndrome coronavirus (MERSCoV) transmission. Euro Surveill 2015;20:14-18.

38. Kim SW, Park JW, Jung HD, et al. Risk factors for transmission of Middle East respiratory syndrome coronavirus infection during the 2015 outbreak in South Korea. Clin Infect Dis 2017;64:551-557.

39. Kim T, Jung J, Kim SM, et al. Transmission among healthcare worker contacts with a Middle East respiratory syndrome patient in a single Korean centre. Clin Microbiol Infect 2016;22:e11-e13.

40. Kim YJ, Cho YJ, Kim DW, et al. Complete genome sequence of Middle East respiratory syndrome coronavirus KOR/KNIH/O02_05_2015, isolated in South Korea. Genome Announc 2015;3:e00787-15.

41. Lu R, Wang Y, Wang W, et al. Complete genome sequence of Middle East Respiratory syndrome coronavirus (MERS-CoV) from the first imported MERS-CoV case in China. Genome Announc 2015;3:eoo818-15.

42. Park WB, Kwon NJ, Choe PG, et al. Isolation of Middle East respiratory syndrome coronavirus from a patient of the 2015 Korean outbreak. J Korean Med Sci 2016;31:315320.

43. Seong MW, Kim SY, Corman VM, et al. Microevolution of outbreak-associated Middle East respiratory syndrome coronavirus, South Korea, 2015. Emerg Infect Dis
2016;22:327-330.

44. Sabir JS, Lam TT, Ahmed MM, et al. Co-circulation of three camel coronavirus species and recombination of MERS-CoVs in Saudi Arabia. Science 2016;351:81-84.

45. Kim JI, Kim YJ, Lemey P, et al. The recent ancestry of Middle East respiratory syndrome coronavirus in Korea has been shaped by recombination. Sci Rep 2016;6:18825.

46. Kim DW, Kim YJ, Park SH, et al. Variations in spike glycoprotein gene of MERS-CoV, South Korea, 2015. Emerg Infect Dis 2016;22:100-104.

47. Kim Y, Cheon S, Min CK, et al. Spread of mutant Middle East respiratory syndrome coronavirus with reduced affinity to human CD26 during the South Korean outbreak. MBio 2016;7:eooo19.

48. Park D, Huh HJ, Kim YJ, et al. Analysis of intrapatient heterogeneity uncovers the microevolution of Middle East respiratory syndrome coronavirus. Cold Spring Harb Mol Case Stud 2016;2:a0o1214.

49. Xie Q, Cao Y, Su J, et al. Two deletion variants of Middle East respiratory syndrome coronavirus found in a patient with characteristic symptoms. Arch Virol 2017;162:24452449.

50. Oh MD, Park WB, Choe PG, et al. Viral load kinetics of MERS coronavirus infection. N Engl J Med 2016;375:13031305.

51. Min CK, Cheon S, Ha NY, et al. Comparative and kinetic analysis of viral shedding and immunological responses in MERS patients representing a broad spectrum of disease severity. Sci Rep 2016;6:25359.

52. Park WB, Perera RA, Choe PG, et al. Kinetics of serologic responses to MERS coronavirus infection in humans, South Korea. Emerg Infect Dis 2015;21:2186-2189.

53. Ko JH, Muller MA, Seok H, et al. Serologic responses of 42 MERS-coronavirus-infected patients according to the disease severity. Diagn Microbiol Infect Dis 2017;89:106111.

54. Choe PG, Perera RAPM, Park WB, et al. MERS-CoV antibody responses 1 year after symptom onset, South Korea, 2015. Emerg Infect Dis 2017;23:1079-1084.

55. Choi WS, Kang CI, Kim Y, et al. Clinical presentation and outcomes of Middle East respiratory syndrome in the Republic of Korea. Infect Chemother 2016;48:118-126.

56. Rhee JY, Hong G, Ryu KM. Clinical implications of 5 cases of Middle East respiratory syndrome coronavirus infection in a South Korean outbreak. Jpn J Infect Dis 2016;69:361-366. 
57. Kim ES, Choe PG, Park WB, et al. Clinical progression and cytokine profiles of Middle East respiratory syndrome coronavirus infection. J Korean Med Sci 2016;31:1717-1725.

58. Ko JH, Park GE, Lee JY, et al. Predictive factors for pneumonia development and progression to respiratory failure in MERS-CoV infected patients. J Infect 2016;73:468-475.

59. Cha RH, Joh JS, Jeong I, et al. Renal complications and their prognosis in Korean patients with Middle East respiratory syndrome-coronavirus from the central MERS-CoV designated hospital. J Korean Med Sci 2015;30:1807-1814.

6o. Kim JE, Heo JH, Kim HO, et al. Neurological complications during treatment of Middle East respiratory syndrome. J Clin Neurol 2017;13:227-233.

61. Choi WJ, Lee KN, Kang EJ, Lee H. Middle East respiratory syndrome-coronavirus infection: a case report of serial computed tomographic findings in a young male patient. Korean J Radiol 2016;17:166-170.

62. Park GE, Kang CI, Ko JH, et al. Differential cell count and CRP level in blood as predictors for Middle East respiratory syndrome coronavirus infection in acute febrile patients during nosocomial outbreak. J Korean Med Sci 2017;32:151-154.

63. Lee H, Ki CS, Sung H, et al. Guidelines for the laboratory diagnosis of Middle East respiratory syndrome coronavirus in Korea. Infect Chemother 2016;48:61-69.

64. Ki CS, Lee H, Sung H, et al. Korean Society for Laboratory Medicine practice guidelines for the molecular diagnosis of Middle East respiratory syndrome during an outbreak in Korea in 2015. Ann Lab Med 2016;36:203-208.

65. Huh HJ, Ko JH, Kim YE, et al. Importance of specimen type and quality in diagnosing Middle East respiratory syndrome. Ann Lab Med 2017;37:81-83.

66. Lee JH, Lee CS, Lee HB. An appropriate lower respiratory tract specimen is essential for diagnosis of Middle East respiratory syndrome (MERS). J Korean Med Sci 2015;30:1207-1208.

67. Kim SH, Ko JH, Park GE, et al. Atypical presentations of MERS-CoV infection in immunocompromised hosts. J Infect Chemother 2017;23:769-773.

68. Chong YP, Song JY, Seo YB, Choi JP, Shin HS; Rapid Response Team. Antiviral treatment guidelines for Middle East respiratory syndrome. Infect Chemother 2015;47:212-222.
69. Hong KH, Choi JP, Hong SH, et al. Predictors of mortality in Middle East respiratory syndrome (MERS). Thorax 2018;73:286-289.

70. Majumder MS, Kluberg SA, Mekaru SR, Brownstein JS. Mortality risk factors for Middle East respiratory syndrome outbreak, South Korea, 2015. Emerg Infect Dis 2015;21:2088-2090.

71. Mizumoto K, Endo A, Chowell G, Miyamatsu Y, Saitoh M, Nishiura H. Real-time characterization of risks of death associated with the Middle East respiratory syndrome (MERS) in the Republic of Korea, 2015. BMC Med 2015;13:228.

72. Kim SY, Park SJ, Cho SY, et al. Viral RNA in blood as indicator of severe outcome in Middle East respiratory syndrome coronavirus infection. Emerg Infect Dis 2016;22:1813-1816.

73. Virlogeux V, Park M, Wu JT, Cowling BJ. Association between severity of MERS-CoV infection and incubation period. Emerg Infect Dis 2016;22:526-528.

74. Jeong SY, Sung SI, Sung JH, et al. MERS-CoV infection in a pregnant woman in Korea. J Korean Med Sci 2017;32:1717-1720.

75. Kim I, Lee JE, Kim KH, Lee S, Lee K, Mok JH. Successful treatment of suspected organizing pneumonia in a patient with Middle East respiratory syndrome coronavirus infection: a case report. J Thorac Dis 2016;8:E1190-E1194.

76. Jeong H, Yim HW, Song YJ, et al. Mental health status of people isolated due to Middle East respiratory syndrome. Epidemiol Health 2016;38:e2016048.

77. Chun S, Chung CR, Ha YE, et al. Possible transfusionrelated acute lung injury following convalescent plasma transfusion in a patient with Middle East respiratory syndrome. Ann Lab Med 2016;36:393-395.

78. Kim JY, Song JY, Yoon YK, et al. Middle East respiratory syndrome infection control and prevention guideline for healthcare facilities. Infect Chemother 2015;47:278-302.

79. Moon SY, Son JS, Lee YH, et al. Middle East respiratory syndrome coronavirus transmission in dialysis unit and infection control interventions in Korea. Infect Control Hosp Epidemiol 2016;37:1514-1516.

8o. Park HC, Lee YK, Lee SH, et al. Middle East respiratory syndrome clinical practice guideline for hemodialysis facilities. Kidney Res Clin Pract 2017;36:111-116.

81. van Doremalen N, Bushmaker T, Munster VJ. Stability of Middle East respiratory syndrome coronavirus (MERS- 
$\mathrm{CoV}$ ) under different environmental conditions. Euro Surveill 2013;18:20590.

82. Bin SY, Heo JY, Song MS, et al. Environmental contamination and viral shedding in MERS patients during MERS-CoV outbreak in South Korea. Clin Infect Dis 2016;62:755-760.

83. Oh MD. Environmental contamination and viral shedding in MERS patients. Clin Infect Dis 2016;62:1615.

84. Song JY, Cheong HJ, Choi MJ, et al. Viral shedding and environmental cleaning in Middle East respiratory syndrome coronavirus infection. Infect Chemother 2015;47:252-255.

85. Kim SH, Chang SY, Sung M, et al. Extensive viable Middle East respiratory syndrome (MERS) coronavirus contamination in air and surrounding environment in MERS isolation wards. Clin Infect Dis 2016;63:363-369.

86. Oh MD. Transmissibility of Middle East respiratory syndrome by the airborne route. Clin Infect Dis 2016;63:1143.

87. Majumder MS, Brownstein JS, Finkelstein SN, Larson RC, Bourouiba L. Nosocomial amplification of MERScoronavirus in South Korea, 2015. Trans R Soc Trop Med Hyg 2017;111:261-269.

88. Nam HS, Yeon MY, Park JW, Hong JY, Son JW. Healthcare worker infected with Middle East Respiratory Syndrome during cardiopulmonary resuscitation in Korea, 2015. Epidemiol Health 2017;39:e2017052.

89. Kim CJ, Choi WS, Jung Y, et al. Surveillance of the Middle East respiratory syndrome (MERS) coronavirus $(\mathrm{CoV})$ infection in healthcare workers after contact with confirmed MERS patients: incidence and risk factors of MERS-CoV seropositivity. Clin Microbiol Infect 2016;22:880-886.

90. Lee JY, Kim G, Lim DG, et al. Seroprevalence of Middle East respiratory syndrome coronavirus among healthcare personnel caring for patients with middle east respiratory syndrome in South Korea. Infect Control Hosp Epidemiol 2016;37:1513-1514.

91. Ko JH, Lee JY, Baek JY, et al. Serologic evaluation of MERS screening strategy for healthcare personnel during a hospital-associated outbreak. Infect Control Hosp Epidemiol 2017;38:234-238.

92. Moon SY, Son JS, Lee YH, et al. Middle East respiratory syndrome coronavirus transmission in dialysis unit and infection control interventions in Korea. Infect Control Hosp Epidemiol 2016;37:1514-1516.

93. World Health Organization. Management of asymptomatic persons who are RT-PCR positive for Middle East respiratory syndrome coronavirus (MERS-CoV): Interim guidance [Internet]. Geneva: World Health Organization, c2018 [cited $2018 \mathrm{Feb} 8$ ]. Available from: http://apps.who.int/ iris/bitstream/10665/180973/1/WHO_MERS_IPC_15.2_eng. pdf?ua=1\&ua=1.

94. Lee J; Rapid Response Team, Kim WJ. Collaborative intervention of Middle East respiratory syndrome: rapid response team. Infect Chemother 2016;48:71-74.

95. Jeon MH, Kim TH. Institutional preparedness to prevent future Middle East respiratory syndrome coronaviruslike outbreaks in Republic of Korea. Infect Chemother 2016;48:75-80. 